REVISTA CHILENA DE LITERATURA

Diciembre 2014, Número 88, 199-214

\title{
LOS “EMPATES” Y LA MEMORIA DEL CAUCHO
}

\author{
Ana Pizarro \\ Universidad de Santiago de Chile \\ ana.pizarro@usach.cl
}

RESUMEN / RESUMO / ABSTRACT

Los "empates" son formas de resistencia pacífica creadas por las poblaciones del Amazonas brasileño y utilizadas para detener el avance amenazador de las empresas de deforestación que invaden su espacio vital. Esta investigación busca demostrar que la disposición a esta confrontación se nutre de una memoria colectiva en la cual es posible identificar los 'ecos' de tres momentos cruciales para la historia del caucho en la región: el sistema de extracción del caucho de fines del siglo XIX y comienzos del XX; el episodio de la "Batalla del Caucho", declarada por el Gobierno de Getúlio Vargas durante la Segunda Guerra Mundial; y las luchas de Acre en la década de 1970, con el inicio de la estrategia de los "empates". En el corazón de esta memoria colectiva se encuentran tanto la tradición oral como el silencio.

PAlABRAS ClAVE: Amazonía, caucho, deforestación, violencia, memoria colectiva.

Os "empates" são formas de resistência pacífica criadas pelas populações da Amazônia brasileira e utilizadas para deter o avanço ameaçador das empresas de desflorestação que invadem o seu espaço vital. Esta pesquisa procura demonstrar que essa disposição ao confronto se nutre de uma memória coletiva na qual é possivel identificar os 'ecos' de três momentos cruciais na história da borracha na região: o sistema de extração da borracha ao final do século XIX e a princípio do XX; o episódio da "Batalha da Borracha", declarada pelo governo de Getúlio Vargas durante a Segunda Guerra Mundial; e as lutas do Acre na década de 1970, com o início da estratégia dos "empates". No coração de esta memória coletiva se encontram tanto a tradição oral quanto o silêncio.

PALAVRAS-CHAVE: Amazônia, borracha, desflorestação, violência, memória coletiva.

The empates are non-violent strategies of resistance devised by the inhabitants of the Brazilian Amazonia in order to stop the threatening advance of companies that are invading and deforesting their environment. This research attempts to demonstrate how this confrontation 
is informed by a collective memory in which it is possible to identify 'echoes' of three crucial moments in this region's history of rubber: the extraction of rubber at the end of the 19th and the beginning of the 20th century; the "Battle of Rubber", declared by the government of Getúlio Vargas during World War II; and the struggles of Acre in the 1970's, which marks the beginning of the strategy of empates. We find, at the core of this collective memory, not only oral tradition but also silence.

KEYWORDS: Amazonia, rubber, deforestation, violence, collective memory.

El tema que intentamos abordar se inscribe en dos ámbitos diferentes que en este caso se articulan. Por una parte, el de la memoria. Los estudios sobre la memoria han tenido un gran crecimiento durante las últimas décadas en nuestro continente en especial por la historia de dictaduras del pasado reciente, y han inscrito su espacio de búsquedas más que nada en las sociedades industriales y posindustriales. El momento industrial marca una clara línea divisoria entre memoria e historia, como ha sido estudiado por Pierre Nora entre otros teóricos del tema, momento de un cambio de ritmos temporales, de urbanización, de un paisaje sonoro diferente, de otra relación del hombre con la vida. Por otra parte se inscribe en los estudios amazónicos. A nosotros nos interesa el funcionamiento simbólico de un momento relativo a sociedades rurales de ritmo y articulación del espacio como experiencias preindustriales, como es el caso de los seringueiros, los recolectores del caucho en Brasil, cuyo medio de trabajo es la selva, y a pesar de tratarse de una industria extractiva, su origen nordestino y su forma y condiciones de trabajo les hace experimentar una temporalidad diferente. Nos interesa en suma observar cómo funciona la memoria en este grupo de historia singular.

Tal como estamos experimentándolo en la actualidad en los países desarrollados y en sus efectos en el resto - "the Rest" en la acertada expresión de Stuart Hall-, el sostenido crecimiento económico de las últimas décadas empieza a dejar en evidencia una crisis ambiental de proporciones. Una crisis financiera, pero que también concierne y afecta a las bases sociales $\mathrm{y}$ ambientales del modelo neoliberal vigente. Es a mediados del siglo XX cuando entran en escena en los países centrales los movimientos ambientalistas y la coyuntura actual tiene su inicio, tal como lo señalan los historiadores, en la década de los sesenta. En lo que cabe a la Amazonía, es interesante conocer lo que ocurre en el Brasil en el período, puesto que se trata del país que posee mayor territorio amazónico de los ocho que la componen (Souza 159). Los años 60 son el momento en que una serie de gobiernos militares 
se toman el poder en Brasil, poniendo en jaque la historia de la región amazónica mediante un modelo de regulación social y política que insiste en el progreso económico como la premisa esencial del progreso social. La región es acoplada forzadamente al Centro-Sur del país, siendo integrada por esa vía al mercado mundial. Esto significa para ella, entre otros, ser víctima de las crisis de éste.

En la Amazonía, los conflictos y los enfrentamientos son muchos y permanentes. Ellos se relacionan con la construcción de hidroeléctricas que alteran el medioambiente y dañan la vida de los habitantes del lugar. Es el caso del convenio de 2009 entre Perú y Brasil, un acuerdo energético para una serie de centrales hidroeléctricas, una de las cuales es Itambarí, en la frontera peruano-brasileña. Otro conflicto es el desencadenado por la central de Belo Monte, en el río Xingú, en Pará, Brasil. Estos conflictos implican deforestación, pero junto a ellos también hay los que tienen que ver con la extracción ilegal de maderas, así como con el surgimiento de depósitos de extracción de oro, tal como en Serra Pelada, en la década de 1980, en donde se generan formas de explotación humana extremas, así como formas inauditas de construcción y destrucción de los tejidos sociales. Respecto de esto último, el arte fotográfico de Sebastián Salgado es conocido internacionalmente y las imágenes del trabajo allí han dado la vuelta al mundo. Muchos otros conflictos pueblan la historia de las últimas décadas en toda la región: los de los movimientos de ocupación de la tierra; aquellos de los garimpeiros, cuyas experiencias narrativas ponen en el tapete diseños culturales diferentes de los conocidos; movimientos sociales de açaizeiros, conflictos de lavanderas, parteras; en Ecuador, enfrentamientos con las petroleras; en Colombia, los campesinos indígenas frente a las FARC, el ejército y los paramilitares, así como las relaciones con el narcotráfico, entre tantas otras. Estas observaciones definen el marco contextual de nuestro objeto de estudio.

Nos interesa en esta oportunidad, la historia del caucho desde la segunda mitad del siglo XIX y en ella la recurrencia de ciertos contenidos de imagen, figuraciones, que funcionan como soporte de declaraciones, relatos orales o actuaciones más contemporáneas y en concreto en las acciones de los años 70 del siglo pasado. Quisiéramos observar en ellas el funcionamiento del pensamiento simbólico a nivel de los sectores populares. Queremos apuntar a la forma en que actúa la memoria, de generación en generación. De acuerdo con el egiptólogo Jan Assman, memoria y cultura tienden incluso a coincidir, en la medida en que es el saber que regula las actividades y percepciones de una sociedad. Pensamos, con Pierre Nora, que esta memoria 
colectiva está directamente ligada a las instancias identitarias del grupo. Nos interesa la memoria en su función acumulativa, pero también en su función transformadora. Tal como veremos en los textos que siguen, la figuración original de fortaleza del seringueiro toma diferentes formas, se resignifica, a lo largo de su historia.

M. K. Schäffauer y Joachim Michael (2003) observan que esta función transformadora tiene que ver con que ella incluye y excluye sentidos y controla el cambio entre el recuerdo y el olvido. Es decir, lleva a cabo procesos de desemiotización y resemiotización de los significantes. Por ello, trabajaremos en dos niveles: por una parte, en lo que se ha llamado "memoria comunicativa", de acuerdo con el análisis de Jan Assman; y por otra en la "memoria cultural", concepto que recubre all knowledge that directs behavior and experience in the interactive framework of a society and one that obtains through generations in repeated societal practices and imitation (Assman 1995). Estas formas de la memoria son posibles de reconstruir tanto a través de la historia oral como a través del documento o del objeto. Es necesario anotar que en la memoria colectiva hay espacio para las alteridades, para la memoria que se resiste a los sistemas del saber colectivo, que contradicen la memoria cultural, es decir, para formas de memoria alternativa. "La memoria está construida por distintas capas -dice Loreto Rebolledo-que se compenetran, se contradicen, coexisten en fin". Su objeto, señala Assman, son las huellas de aquello que las formas del pasado excluyen. Se trata de formas que están presentes en las estructuras conectivas que establecen entre las generaciones la continuidad comunicativa. Esta continuidad le da forma de archivo a aquello que fue repertorio (Diana Taylor 2003). Nos interesa esta última diferenciación.

A partir de 1964, con la toma del poder por los gobiernos militares, la Amazonía brasileña experimenta la expansión de la frontera económica en el Acre, zona de seringales y castañales por excelencia. Esto significa la entrada de la hacienda, la gran producción ganadera. Surge por otra parte Medellín 1968, en donde la Iglesia latinoamericana se posiciona a favor de la transformación de la realidad social. Los años de fines de los sesenta hasta mediados de los setenta serán un período de auge de la lucha de masas en el continente apoyada por la Teología de la Liberación.

En esta línea de desarrollo presentaremos en este artículo primeramente la cuestión de los "empates", el fenómeno social acreano de lucha gremial y ambientalista, para luego mostrar cómo ellos tienen un marco de referencia que es la memoria colectiva. Este marco se sitúa por lo menos en dos instancias 
históricas que la misma memoria destaca y a las que vuelve con insistencia, lo cual pone en evidencia su impronta en la cuestión identitaria, que ejerce como sustento de las estrategias políticas elaboradas por los activistas de los años 70 del siglo XX.

En diciembre de 1988, un título de periódico conmociona a un público local e internacional a la vez. Es la muerte por asesinato, muerte "anunciada", de Francisco Alves Mendes Filho, en Xapurí, Acre brasileño. Se trata de una conmoción que deja en evidencia al movimiento de los seringueros, los trabajadores del caucho, que comenzaba recién a ser conocido en el terreno internacional. Otros movimientos sociales, sobre todo en Amazonía, nunca salen a la luz pública a ese nivel. Permanecen en un silencio compartido por el temor o en el silencio cómplice de la prensa local. En el caso de la muerte de Chico Mendes, la situación es diferente porque su actividad política había trascendido de lo local al terreno internacional. Otro dirigente, Wilson Pinheiro, Presidente del Sindicato de Seringueros, había sido ejecutado por el poder de los latifundistas en Brasilia, en 1980. Era, junto con un sacerdote de la Teología de la Liberación, un referente ético fundamental en la vida del primero. El precio de los pistoleros había sido de 600 cruzados (unos 230 euros de la época). El año anterior a la muerte de Chico Mendes, habían sido asesinados ochenta dirigentes y solo hubo juicio en dos casos (Shoumatoff 1991). Como era común en la zona, su muerte fue "anunciada" el año anterior y ya se preveía luego la de Wilson Pinheiro.

El movimiento seringuero había adquirido con Pinheiro un perfil particular: él inicia el sistema de "empates". Chico Mendes lo desarrollará más tarde, como forma de dar la lucha para obtener la legalización de las llamadas "reservas de extracción". Ellas buscan establecer territorios protegidos de la ganadería y, por tanto, buscan impedir la tala indiscriminada de árboles. Ello porque el gran problema de los seringueros era la llegada a la zona de grandes terratenientes que buscaban extender sus terrenos para la ganadería, lo que significaba la muerte de los bosques y de la vegetación en general. La muerte de la selva, como ha ido sucediendo en diferentes lugares de Amazonía por razones diferentes. Con esta lucha, los trabajadores del caucho protegen por una parte su subsistencia y, por otra, el recurso natural. En realidad, la protección de la primera implica la del segundo y Chico Mendes era un dirigente local que defendía la supervivencia de su grupo frente a la expansión de los hacendados, los que a partir de la instalación de la propiedad agraria en la región, en los años 70, se habían apropiado a través de la compra y diversos métodos coercitivos de la zona de Acre, implantando el sistema latifundista. 
Su movimiento y su gestión se daban en un momento estratégico en que comenzaba a nivel internacional a manifestarse masivamente una conciencia de la importancia de la relación del hombre con la naturaleza, a través del surgimiento del movimiento ambientalista. Esta situación histórica llevó a que su discurso comenzara a ser leído, en ese terreno, más allá de lo local. $\mathrm{Su}$ capacidad de liderazgo lo conducia rápidamente al aglutinamiento de partidos, grupos, voluntades en torno a la defensa de la Amazonía, en donde organizó y lideró la Alianza de los Pueblos de la Selva. En ese momento, lo que en Brasil aparecía como un peligro, en otros países comenzó a visualizarse como una virtud. El dirigente comenzó a ser conocido a nivel internacional.

La lucha a través de los "empates", esa nueva forma de enfrentar al poder, con su espectacularidad, su pacifismo y su arrojo, caracterizó al movimiento seringuero de la época.

Así perfilaba Chico Mendes esta estrategia:

A partir de 1975 empieza a nacer una consciencia [sic], y se organizan los primeros sindicatos rurales paralelamente a la actividad de la Iglesia Católica. Todo ocurrió de manera muy lenta hasta 1980, cuando se generalizó por toda la región el movimiento de resistencia de los seringueiros para impedir la gran deforestación. Nos inventamos el famoso "empate", nos poníamos delante de los peones con sus sierras mecánicas e intentábamos impedir la deforestación. Era un movimiento de hombres, mujeres y niños. Las mujeres tenían un papel muy importante como línea de frente, y los niños se utilizaban para evitar que los pistoleros disparasen. Teníamos un mensaje para los peones: nos reuníamos con ellos y les explicábamos que si destruían la selva no tendrían con que [sic] sobrevivir y, así, muchas veces se nos unían. El mayor enemigo era la policía contratada por los hacendados. Durante ese período hubo muchas detenciones y palizas" (cit. en Ferrer 38).

Desde el primer empate, en 1976, se había logrado el establecimiento de una serie de reservas extractivistas, a través de una lucha de arrojo, pero sin violencia, al modo de Gandhi o Martin Luther King.

En la perspectiva de una mujer participante en esta forma de lucha grupal, el acontecimiento se narra, sin el razonamiento de Chico, de un modo más vivenciado:

Tinha uma derrubada lá no Recanto, onde cortaram as terras. Agora nós vamos empatar! Quem é que vai na frente? As mulheres, ajunta tudo quanto é mulher e bota na frente. Tinha 25 policial e 1 
tenente, guarnecendo os peão. Agora é que vão matar nós tudo! Ai nós fomos, saímos de madrugada. Ia tudo bem na frente, era bem umas 50 mulher ou mais e os homem atrás. Quando nós chegamos lá onda tava os policial, menino, vinha chegando uns homens assim, uns trazia os moto serra, outros trazia machado, uns baldes -acho que era gasolina-menino, esses homens quando avistou nós soltaram tudo isso no chão e avuaram pra trás na carreira! Aí eles pegaram os fuzil, tudo baionetas escalada no nosso rumo. Ai disse assim: "Vamos cantar já o hino nacional que eles baixa essas armas". Ai eu e a Marizinha, que é a ex-mulher do Raimundo de Barros, e nós era que comandava, sabe? Que tinha mais coragem! Ai ela, vamos cantar o hino nacional. Ai toquemos, cantando o hino nacional. Todo mundo tirou o chapéu da cabeça, arriou assim, até o tenente (Montysuma 2011, 170-171).

Ahora bien, ¿cuál es el modo de funcionamiento a nivel de memoria colectiva de estos acontecimientos, tal como son perceptibles en la oralidad?

Nuestra tesis es que esta memoria colectiva funciona a partir de especies de ecos referenciales que constituyen instancias identitarias. En estos ecos existen tres momentos cruciales para la historia del caucho en la región: en primer término, el sistema que se llevó a cabo a fines del siglo XIX y comienzos del XX con los "coroneles de barranco", los grandes propietarios de las tierras caucheras de poder omnímodo. Luego, el episodio de la "Batalla del Caucho"; y, en tercer lugar, las luchas de Acre en los años 1970 y la estrategia de "empates". Para recuperar estos hitos a través del sujeto popular nos aproximaremos a publicaciones de literatura de cordel y publicaciones artesanales locales tanto actuales como de los períodos referidos. El período actual, que comenzamos a estudiar ahora, tiene que ver también con estos ciclos. Se trata ahora de la organización sindical de los seringueros.

El primero de los momentos señalados corresponde al episodio del "desbravamento", la entrada en la selva y la apropiación de ella por el hombre, de la que la voz que enuncia se siente orgullosa, señalando porque nós somos o fim de esta geração de bravos:

Este desbravamento -dice-foi feito pelos nossos antepassados que forçados pela histórica seca do 77, vieram para a região, viajando em tombadilhos de navios e outros meios de transporte penetrando nos rios não desbravados, principalmente no Purus, Acre e Juruá, expondo-se a tudo. 
Para que estas regiões se tomassem no futuro território brasileiro morreram centenas acometidos pelo impaludismo, picadas de cobras, devorados pelas onças e outras feras e por fim mortos nos combates travados contra as tropas peruanas, que invadiram o Purus pela nascente (Brito Nunes $\mathrm{s} / \mathrm{p}$ ).

El autor de este relato es un seringueiro nacido en 1921 en el seringal "Muiraquitã", colocação Porto Central, Alto Rio Purus, que, habiendo podido ir a hacer estudios y participado en la Batalha da Borracha, tuvo un largo camino hacia la tranquilidad económica y el reconocimiento social. En el escrito se trata de un exitoso que da cuenta de su vida. Hay en el relato entonces dos elementos que se encontrarán presentes también en otros, el sentido del dolor de lo vivido y el de la fuerza con que se enfrentó la situación, esto tanto a nivel individual como colectivo.

Es necesario recordar que esta apertura de la selva significa también el trabajo esclavo en los seringales, en donde el trabajador inmigrante, en el caso de Brasil, indígena en Colombia, Perú y Bolivia, experimenta el sistema de aviamento, la exigencia de entrega excesiva de caucho, la tortura y la muerte, como sucedió en el caso peruano de la "casa Arana", en un modus operandi que fue común a las diferentes zonas de extracción de esta materia prima en un período de alza de su precio en los mercados internacionales.

Antonio Amaro da Silva, por otra parte, es un viejo yagunzo, "contador de historias". Para esta parte del Brasil, situada en la Amazonía Occidental, no hay fuentes documentales. Es por eso que el autor de este otro escrito dice basarse en la tradición oral. Se trata de conversaciones en grupo en donde el narrador principal es Seu Amaro, que sabía del odio popular en contra de la autoridad, ya que era un sobreviviente de la guerra de Canudos y, como tal, va a parar al Amazonas. En este sentido, es importante el punto de vista desde el cual se narran las historias.

Segundo pregaba Antonio Conselheiro - dice- quando a noite aparecia na porta da igrejinha, os homens tinham nascido para cumprir missão sobre a terra. Essa, seria a prática do bem. Não se justificava, portanto, a existência de ricos e de pobres, dos que mandavam e dos que tinham apenas o direito de obedecer; dos que sofriam os rigores da fome e da miséria; dos que viviam na opulência e abusavam dos fracos (Brito Nunes s/p). 
Es importante la consignación de esta conciencia de la injusticia social que se desplaza en los relatos a lo largo del siglo XX. Sobre la caída de la borracha, en 1913, describe: hacia falta de tudo. De sal, de açúcar, de farinha e de munição para armas de fogo. O único caminho era o rio para fugir de aquele estado de miséria (Brito Nunes 1996: 243). El imaginario que revelan los textos pertenece y no pertenece a la experiencia directa de los acontecimientos; su relato es una crónica con forma de "memorias" o "historia de vida". Ellas se escriben por una necesidad de comunicar a los de su mismo grupo: do seringueiro para o seringueiro, señala un subtítulo; o bien para que los acontecimientos permanezcan y los conozcan los filhos, netos e bisnetos. Se insiste en que es para que el desbravamento no se olvide, pues se trata narraciones que no están em nenhum livro. Nos situamos entonces en una narración más próxima a la memoria que a la historia, puesto que, siguiendo la distinción que Pierre Nora hace entre ambas: la mémoire s'enracine dans le concret, dans l'espace, le geste, l'image de l'objet. L'histoire ne s'attache qu'aux continuités temporelles. Y afirma: mémoire, histoire: loin d'être synonymes, nous prenons conscience que tout les oppose (Nora XIX).

La crónica del "desbravamento" - a fines del XIX y comienzos del XX en general- que hacen estos textos se orienta a una experiencia que forma parte de la conciencia actual, que está en la cotidianeidad de las historias familiares y que apunta siempre en dirección a la valentía, al heroísmo de quienes allí fueron -que en su mayoría eran inmigrantes nordestinos en el caso brasileño- y apunta también al nacionalismo en un momento de incipiente construcción de la nación: ellos fueron a hacer patria desentrañando la selva o luchando frente a los peruanos, por ejemplo. Se trata de un período en que los límites geográficos están difusos y los gobiernos se preocupan de llevar comisiones para marcar las fronteras. Es así como llega al Alto Purus Euclides da Cunha, cuya conclusión es una afirmación categórica o seringueiro é um forte. La memoria ha ido elaborando así el sentido de los acontecimientos y este sentimiento de fortaleza es el marco colectivo que da sentido a la memoria individual.

Pero hay también una cierta elaboración en la direccion de clase, como pudimos observar en alguno de los textos: estamos en el momento en que surgen los llamados "barones del caucho" en toda la región, pues éste es una materia prima fundamental para el salto industrial y de las comunicaciones de comienzos del siglo XX, al haber adquirido un alto precio en los mercados internacionales. Es el momento en que, a las condiciones de vida dura de los seringueiros, se agrega la explotación que hacen de ellos las empresas 
caucheras dirigidas por estos llamados "barones" por su poder -Suárez en Bolivia, Arana y Fitzcarraldo en Perú, entre los más conocidos, otros en Brasil-, que pone en la prensa internacional, como es el caso del Putumayo en el Perú, los grandes escándalos de esclavización, muerte y tortura de estos trabajadores para obtener más volumen de producción. Los textos, en general, muestran la relación de explotación y, en el caso brasileño como se trata de nordestinos, muestran también que a la conciencia de patria, de bravura, de expoliación, se suma el sentimiento de nostalgia por la tierra de origen, el Nordeste, que a menudo también llaman "patria" y en donde en general quedó su familia. En 1916, se publica un folheto de Firmino Teixeira do Amaral, O rigor no Amazonas, que en algunas de sus treinta sextillas anota el engaño de los patrones:

Os patrões dizem assim

Quando querem iludir,

Mostram vantagens ao freguês

Para com ele subir

Para ir é muito fácil

O diabo é para vir.

Quem se fiar nessas loas

Lá vera no fim do ano:

$O$ mel transformado em fel

A esperança em engano

E o seringueiro dizer

-Ah! Coração de tirano!...

(Teixeira do Amaral119-120)

Los estratos mnémicos entonces se compenetran. Establecen jerarquías, en este caso la explotación, la bravura, la nostalgia toman primeros planos. Pero también el olvido es parte de la memoria y entonces se negocia con él.

El antropólogo colombiano Juan Alvaro Echeverri analiza la experiencia del grupo muinane en Colombia, que fue objeto de ejecuciones, torturas, mutilaciones, violaciones y toda forma de explotación en el tiempo de la Casa Arana. Este es el lugar emblemático en donde sucedieron las llamadas "matanzas del Putumayo", descritas por el juez peruano C. Valcárcel y por el juez Paredes que se encargaron del caso a costa de enfrentamientos con el poder de Julio Arana y su grupo. Ellas dieron lugar a los "escándalos del Putumayo", y la cuestión fue llevada hasta las cortes inglesas en la medida en que capitales de esta nacionalidad estaban incorporados allí. 
Los muinane han necesitado volver hace poco allí, en 1993. Apunta el investigador de los muinane que los descendientes de los grupos que sobrevivieron al auge cauchero se refieren a las memorias de ese tiempo como pertenecientes a lo que llaman el Canasto de las Tinieblas. En contraste con ese oscuro canasto de malas memorias, hablan también de un Canasto de Vida, donde están colocadas las semillas del futuro, mirando el crecimiento y dejando atrás los peligrosos recuerdos de violencia y brujería del pasado (471).

Ellos peregrinaron hasta el lugar actual de la Casa Arana, en Colombia, que hoy es un lugar que se puede visitar. Necesitaban enfrentar una memoria que durante décadas no habían logrado asumir. Muchos de ellos envejecieron lejos de sus tierras, otros habían nacido lejos de ella y aquel era el territorio ancestral.

Este territorio era conocido por los ancianos en palabras y memorias, pero ellos no habían retornado allí desde la infancia. "Para ellos este territorio no es solo un lugar geográfico, es la inscripcion de la vida y la memoria en el paisaje", afirma el investigador, ambos quedaron amputados con los acontecimientos de la Casa Arana. Y agrega: "necesitaban ir hasta allá con sus hijos para mostrarles y retomar el hilo de sus vidas". Caminaron cinco días y llegaron. Entonces así hablaron a los antepasados que habían vivido allí y habían experimentado las historias del horror:

Aquí, abuelito Jeevadeha, usted vivía y usted está. Somos sus nietos y hemos llegado. A este punto llegamos y pisamos esta parte. ¿Cómo está? Venimos bien. Con buen pensamiento. Los que somos sus huesos venimos de regreso, los nietos que nacimos después de ustedes... Venimos buscando las buenas palabras que hay en usted: la palabra de vida, la palabra fría, la palabra de estimación. Tiene que darnos esas palabras. Estamos limpiando encima de usted. Creíamos que estábamos solos, usted está aquí. A eso vinimos, donde usted hemos llegado. Esto le digo a usted (Echeverri 2012).

Aquí, entonces, no se invoca a la violencia, vista históricamente como negativa, a pesar de lo padecido. Para este grupo tocado con fuerza por los episodios de la Casa Arana a comienzos del siglo XX, se trata de no mirar hacia atrás, negociar con la memoria a través del olvido, el silencio, y mirar hacia delante, construir futuro, "Canasta de vida".

El segundo momento que marcan los relatos tiene que ver con un nuevo episodio, ahora de los años 1940 en Brasil, llamado la Batalha da Borracha. Como se sabe, durante la Segunda Guerra Mundial, un tratado con los Estados Unidos llevó a Getúlio Vargas a comprometer gran cantidad de caucho para 
enviar a este país. El caucho había tenido su gran caída en 1913, luego que aparecieran las plantaciones de Malasia hechas por los ingleses. Pero ahora no era posible el transporte debido a la guerra. Entonces, el Gobierno de Vargas, que había entrado a la contienda, llevó a cabo una campaña publicitaria enorme apelando al nacionalismo. Se buscó fundamentalmente trabajadores en el nordeste. Quien no quisiera ir al frente de batalla tenía la batalha da borracha como alternativa patriótica. Se trataba de luchar por el Brasil, de defenderlo. Hace un poco más de un año, a fines de 2012, antes de que muriese, la investigadora tuvo la posibilidad de conversar con Vicência Bezerra da Costa, de 84 años, una de las pioneras de la colonización nordestina en Acre, llamada afectuosamente por los vecinos Tia Vicência, de Xapuri, muy conocida en el área por ser una de las sobrevivientes de la época. Yo tenía desde luego la versión crítica del episodio, aventura política engañosa de un líder populista que le costó más vidas al Brasil que las del frente armado. Entonces le pregunté con ingenuidad: ¿Y por qué fueron a la Batalha da Borracha? Me contestó, con un gesto sorprendido por la pregunta: ;A gente foi pra defender ao Brasil! Efectivamente, a este llamado realizado en términos escandalosamente patrioteros, la gente respondió masivamente y con ingenuidad. Esta gran tragedia, producida por una situación de manejo político voluntarista, llevada a cabo en las peores condiciones de protección, reeditó el relato del caucho de comienzos de siglo, a partir de la excusa de un nacionalismo absurdo. Este nacionalismo impregna la imagen popular del episodio en el área, hasta hoy. Los textos anotan en relación con un "soldado": porque se embrenhou nas selvas para o cumprimento de uma missão espinosa, dando prova de que era um bom patriota (Alves de Oliveira, s/f: 08). O bien:

O través desses acontecimentos com Alfredo José Roque, podemos analisar como foi perigosa a lida do soldado da borracha e finalmente de todos aqueles que lutaram e continuam lutando dentro das selvas amazônicas com a finalidade de sobreviver, produzindo borracha, fazendo agricultura para o seu consumo e engrandecendo a nossa Pátria, com o desejo de recompensa (Alves, s/f: 10).

El episodio llevó a miles de nordestinos nuevamente a la selva amazónica en condiciones paupérrimas. Jaime da Silva Araújo escribe "Pai Nosso do Seringueiro", texto emblemático de la situación desde la perspectiva de quienes trabajan (Vieira de Souza 1). Así lo expresa también un texto musicalizado de Raimundo Alves llamado A lida do seringueiro: 
Seringueiro lá na mata, nem parece um cidadão,

Naquela lida ingrata, trabalhando a bem da pátria e do progresso do patrão;

Atacado pelos insetos, sarampo, febre e sezão,

Pouco dinheiro ele ganha e tem a farofa de banha como alimentação;

Ele sempre acorda é todo ensanguentado

porque quando está dormindo, pelo morcego

é sangrado.

É uma vida de suplício, e muitas noites com isso passa o tempo acordado;

Dorme pouco na noite, levanta de madrugada, porque de manhã bem cedo vai cortar a sua estrada,

Quando sai é de carreira, com espingarda e cartucheira, temendo a onça pintada;

Acreditem meus leitores no que estou narrando,

O sofrer do seringueiro é como estou contando:

Trabalha com muito medo e também não tem sossego com a carapanã ferrando.

Como podemos observar, la memoria colectiva de este episodio de los años 1940 destaca, por una parte, la valentía de quienes participaron en la segunda etapa de recolección de caucho; por otra parte, apunta al patriotismo y a una perspectiva crítica de las desigualdades sociales. Hay también, en este caso, la dimensión de la nostalgia, ya que los participantes fueron, como señalábamos, en su mayoría nuevamente nordestinos.

Me interesa entonces observar el movimiento de la memoria colectiva. Éste nos muestra-dado que los textos de cordel son de la época a la que se refieren y también en parte actuales, es decir, con perspectivas del momento de los hechos narrados y también contemporáneas a nosotros- cómo el episodio de los "empates" al que nos aproximamos al comienzo, que ha implicado una enorme valentía y conciencia de la injusticia de parte de sus protagonistas, se da en el marco de una especie de caja de resonancia de situaciones que han ido construyendo una memoria, una identidad. Es decir, en cada empate está la latencia de la "Batalha da Borracha" como la de los episodios del "desbravamiento", en una especie de evidencia de la afirmación de Euclides da Cunha en el sentido de que el seringueiro es, sobre todo "um forte", pero además, un fuerte con dignidad. Así lo describía: É mais forte; é mais digno. 
Resignou-se à desdita. Não murmura. Não reza. As preces ansiosas sobem por vezes ao céu, levando disfarçadamente o travo de um ressentimento contra a divindade; e ele não se queixa (Da Cunha).

Estamos, entonces, frente a textualidades que dan cuenta, por una parte, de un ejercicio de la memoria que reactualiza, que presentifica dimensiones éticas y sentimientos de episodios que se han extendido a lo largo de casi un siglo, pero que son actuales colectivamente y funcionan como estructura de significaciones condicionando el actuar en el episodio de los empates. Hay una historia que ha construido al seringueiro, como a su mujer y a sus hijos, que es a la vez un punto de apoyo pero también un elemento que funciona como impulso detonante en el momento de enfrentar el empate y de situarse frente al agresor. Son capas mnémicas que jerarquizan valores, figuraciones simbólicas que se suceden resignificando contenidos. La violencia ejercida contra ellos tiene su respuesta en un "Canasto de vida", con los empates. El sentido es de defensa, de reactualizacion del valor. Y hay que tener valor para apostar y poner a los niños y las mujeres en primera linea de fuego, apelando a la reserva de humanidad del agresor. (También se apuesta a la valoración de su imagen frente a la comunidad nacional e internacional). Es una actitud de profunda valentía y arrojo, y es al mismo tiempo una resignificación, un cambio del signo de la violencia ejercida en contra de ellos históricamente, que apuesta a confiar en la conciencia del ser humano, aunque sea agresor. Se trata de una reelaboración simbólica del recuerdo, que resignifica el dolor y lo pone en la Canasta de Vida.

Observa Pierre Nora cómo los habitantes de sociedades rurales, frente a lo que sucede con la mundialización de hoy, no necesitan realizar un esfuerzo extraordinario para acceder al pasado. Son sociedades que habitaban un "milieux de mémoire", espacio en donde presente, pasado y futuro estructuran una argamasa temporal en la que funciona la sociedad. Así, la memoria forma parte de la vida, es siempre llevada por grupos vivos, y por eso ella está en evolución permanente:

Ouverte à la dialectique du souvenir et de l'amnésie, inconsciente de ses déformations succéssives, vulnérable 'a toutes les utilisations et manipulations, succeptible de longues latences et de soudaines révitalisations. L'histoire est la réconstruction toujours problématique et incomplete de ce qui n'est plus... (...) La mémoire est un absolu, l'histoire ne connait que le relatif (Nora XVIII-XIX). 
En el caso de los seringueiros se trata de sociedades rurales o ruralizadas, en donde el relato, por sus características propias, es más cercano a los llamados "milieux de mémoire" que a los "lieux de mémoire", en los cuales el acontecimiento ha pasado por un proceso de simbolización mayor que se concretiza en un referente. Así, sus relatos pertenecen mucho más al repertorio que al archivo, están más cerca de la experiencia que de su racionalización. La vivencia de esa memoria se actualiza y se resemantiza en el presente: en los protagonistas del "empate" el dolor histórico de los episodios siempre presentes del debravamiento y de la "Batalha da Borracha" da lugar a una apuesta de sufrimiento con valor, que apela a la ética del agresor. En este gesto, el del "empate" se juega también el arrojo, la audacia, la dignidad y la fortaleza de los "desbravadores".

Podemos observar, entonces, que los relatos a que nos hemos referido tienen otros relatos detrás, que en los episodios que narran y en la forma de enunciarlos hay ecos de otras instancias de una memoria que es cercana porque está situada en espacios rurales en donde la temporalidad se construye en síntesis. Podemos observar un presente en donde reverbera el pasado que adquiere profundidad, espesor y cada elemento toma así una significación. Pareciera que el presente sin memoria carece de referentes para significar el futuro. También que la memoria no es necesariamente oralidad ni texto, sino que ella actúa, se elabora y resignifica también en el silencio.

\section{BIBLIOGRAFÍA}

Assmann, Jan. "Collective Memory and Cultural Identity". New German Critique 65 (1995): 125-133.

Brito Nunes, Jersey de. Memórias de um seringueiro. Digitado, 1996.

Cunha, Euclides da. Amargem da História. Web.<www.nead.unama.br >

Echeverri, Juan Alvaro. "Canasto de vida y canasto de las tinieblas: memoria indígena del tiempo del caucho". El aliento de la memoria. Antropología e historia de la amazonía andina. Eds. François Correa Rubio et al. Bogotá: Institutfrançaisd'étudesandines -IFEA; Universidad Nacional de Colombia. Facultad de Ciencias Sociales; Centre National de la Recherche Scientifique-CNRS, 2012.

Ferrer, Núria. "Chico Mendes. La defensa de la vida” (entrevista). Ecología política $\mathrm{N}^{\circ} 2$ (1990): 37-47.

Montysuma, Marcos. "Lecturas de género y medio ambiente a través de los recuerdos y experiencias de las mujeres deXapuri-Acre (1964-2006)". Eds. Necoechea Gracia, Gerardo \& Antonio Torres Montenegro. Caminos de historia y memoria en América Latina. Buenos Aires: Imago Mundi, 2011. 167-180. 
Nora, Pierre. "Entre mémoire et histoire". Les Lieux de mémoire. La République, Tomo 1. Paris: Gallimard, 1984.

Oliveira, Raimundo Alves de. O soldado da borracha. Fundação Cultural do Estado do Acre, s/f.

Rebolledo, Loreto. Memorias del desarraigo. Testimonios de exilio y retorno de hombres y mujeres de Chile. Santiago: Catalonia, 2006.

Salles, Vicente. Repente e Cordel. Literatura popular en versos na Amazonia. Rio de Janeiro: Funarte, 1985.

Schäffauer, Markus Klaus y Joachim Michael. "Géneros entre medios y memoria: pasajes cronotípicos". Figuraciones 1-2, 2003.

Shoumatoff, Alex. "Murder in the rainforest - The Chico Mendes story". Londres: Fourth Estate, 1991.

Taylor, Diana. The archive and the Repertoire: Performing Cultural Memory in the Americas. Durham; Londres: Duke University Press, 2003.

Vieira de Souza, Joao. Vida de Seringueiro, Sindicato de Trabalhadores Rurais de Plácido Castro. Comissão Pastoral da Terra Regional Acre. 